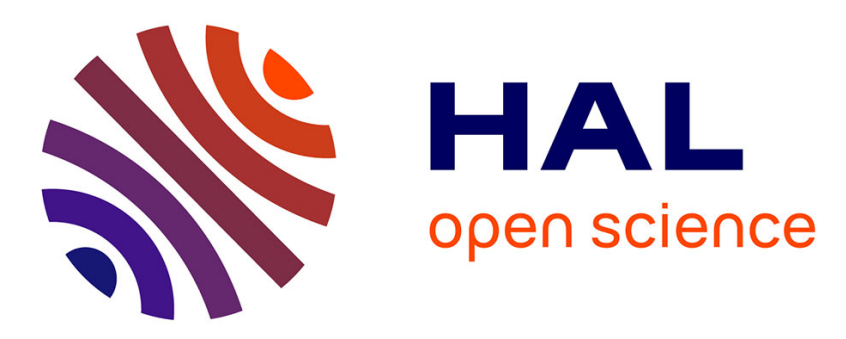

\title{
Micro EDM milling with automated electrochemical fabrication of the cylindrical microtool
}

\author{
Y Layouni, G Girardin, A Benilov, J Etzkorn, V Semet, P Morin, M Cabrera
}

\section{To cite this version:}

Y Layouni, G Girardin, A Benilov, J Etzkorn, V Semet, et al.. Micro EDM milling with automated electrochemical fabrication of the cylindrical microtool. 7th International Conference on MultiMaterial Micro Manufacture, Nov 2010, Bourg en Bresse and Oyonnax, France. hal-01306813

\section{HAL Id: hal-01306813 https://hal.science/hal-01306813}

Submitted on 25 Apr 2016

HAL is a multi-disciplinary open access archive for the deposit and dissemination of scientific research documents, whether they are published or not. The documents may come from teaching and research institutions in France or abroad, or from public or private research centers.
L'archive ouverte pluridisciplinaire HAL, est destinée au dépôt et à la diffusion de documents scientifiques de niveau recherche, publiés ou non, émanant des établissements d'enseignement et de recherche français ou étrangers, des laboratoires publics ou privés. 


\title{
Micro EDM milling with automated electrochemical fabrication of the cylindrical microtool
}

\author{
Y. Layouni, G. Girardin, A. Benilov, J. Etzkorn, V. Semet, P. Morin, M. Cabrera \\ Institut des Nanotechnologies de Lyon, UMR 5270 CNRS INSA ECL UCB, Université Claude Bernard Lyon 1 \\ 43 Bd du 11 Novembre 1918, F69622 Villeurbanne Cedex, France
}

\begin{abstract}
Micro electrical discharge machining in the milling configuration ( $\mu$ EDM milling) allows machining of complex microparts in a flexible way by controlling the erosion process along the 3D path of a thin cylindrical microtool. This technique is attracting growing interest for the processing of mesoscopic and/or high aspect ratio parts. A bottleneck in the development of this technology is the fabrication of thin diameter tools with large aspect ratios. In this paper, we introduce an innovative $\mu E D M$ milling machine along with a machine entirely developed in our laboratory used to form microtools by electrochemical fabrication. The fabrication process is performed automatically according to a method derived from the technology originally developed for the fabrication of Scanning Tunnelling Microscope (STM) tips. Examples of fabricated tungsten microtools with 4 to $10 \mu \mathrm{m}$ diameters over a 300 to $800 \mu \mathrm{m}$ lengths are presented along with preliminary data about the machining of microfluidic channels in stainless steel and titanium.
\end{abstract}

Keywords: microelectrode, electrochemistry, micromachining, micro EDM, electrical discharge machining

\section{Introduction}

Micro EDM milling ( $\mu$ EDM milling) allows machining of complex microparts in a flexible way by controlling the erosion process along the 3D path of a thin cylindrical microtool [1]. This technique is attracting growing interest in microtechnology for the processing of mesoscopic and/or high aspect ratio parts, especially when the parts are made in material difficult to machine by other means (EDM is compatible with all kinds of electrically conducting materials). Examples of such parts are stainless steel micro-reactors for microchemistry, micromolds in hard metals for injection molding, and biocompatible titanium objects for medicine. Conventional microfabrication processes such as Reactive Ion Etching, Focused Ion Beam, and LIGA are not optimized for such materials. Contrary to $\mu E D M$ milling, these technologies are expensive and require skilled operators. However, their resolution is superior to $\mu E D M$ milling. Therefore, it is important to improve the machining resolution of $\mu E D M$ milling.

A bottleneck in improving the resolution of $\mu$ EDM milling is the fabrication of the cylindrical microtools. Such tools are traditionally made by reverse EDM, wire EDM, WEDG or micromilling $[1,2,3]$ but these processes require dedicated expensive machinery. The best tools that have been reported have diameters between 2 to $5 \mu \mathrm{m}$ with a residual stress which is not negligible [4]. However, in commercial $\mu$ EDM milling machines, the tool diameter is much higher. Therefore, it is necessary to develop new ways to easily obtain microtools with controlled geometry, thin diameter, and high aspect ratio.

Electrochemical dissolution is among the different techniques which may be considered for this purpose because it is a fast and low cost technique. However, the tool geometry is not ideal. The reason is that electrochemical dissolution naturally leads to a conical shape which requires complex compensation during the fabrication in order to obtain a cylindrical shape [5].

Previously we have suggested to prepare the tool with a low cost electrochemical fabrication process according to a method derived from the technology originally developed for the fabrication of Scanning Tunnelling Microscope (STM) tips [6]. These tips can be made with the "drop off" effect [7], which leads to a conical micrometric shape with an apex with a few atoms. Such a shape at micrometric scale is interesting but irrelevant for EDM milling due to the low aspect ratio. However, as we shall see below, we have found a way to adapt the process to change the geometry of the device to better match our purpose.

In this paper, we describe an innovative $\mu$ EDM milling machine with automated in situ electrochemical fabrication of the microelectrode tool [8]. The drop-off technique has been avoided in a simple and innovative manner so as to obtain cylindrical ultrathin microtool with very high aspect ratio [9]. Examples of fabricated tungsten microelectrodes and preliminary data about the micromachining of microfluidic channel of stainless steel and titanium are reported. First trials of $\mu$ EDM performed in dry air demonstrate that the machining resolution is in the micrometric range.

\section{Experimental set up}

\subsection{Overview}

The machine developed in our laboratory has basically two functions: to fabricate the cylindrical tool by electrochemical dissolution of a metallic rod and to machine parts by $\mu \mathrm{EDM}$ milling with this microtool. 
The principle of operation is shown in Fig. 1. The machine has two vats which are displaced by a $X Y$ translation stage. Firstly, the vat for the tool fabrication, which is filled with an electrolyte, is placed below the rod. A vertical $Z$ stage raises the stage and the rod is immerged in the electrolyte. A voltage is then applied and the rod is progressively made thinner, as explained below, so as to obtain the target diameter. When this is achieved, the stage is lowered and the EDM vat, with the part to machine, is placed below the tool. The part is then machined by $\mu E D M$ milling with deionised water. When the tool is worn, the stage is lowered and the electrochemical vat is placed again below the tool for tool regeneration. This involves removing the worn tool by electrochemistry and introducing a new section of the rod by a feeding system (still in development) in order to repeat the tool fabrication process. In the present machine configuration, all translation stages are based on step by step motors with $1.25 \mu \mathrm{m}$ halfstep resolution.

\section{(a) Fabrication of microtool}

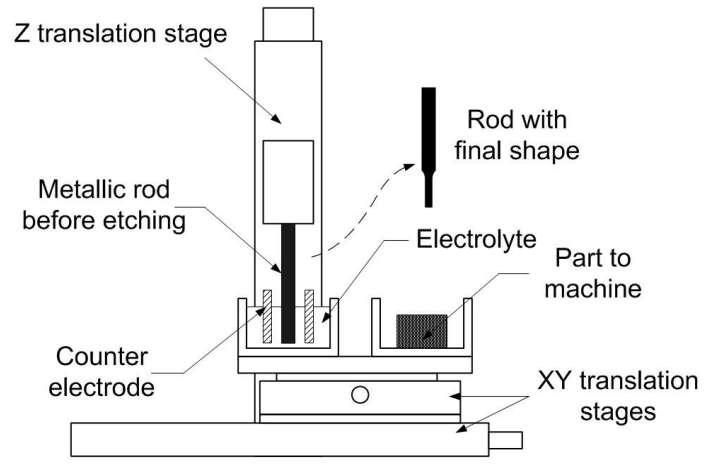

\section{(b) $\mu$ EDM milling}

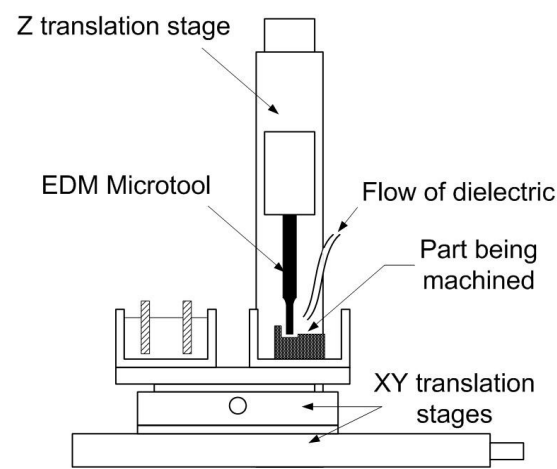

Figure 1. (a) Machine showing the electrochemical fabrication of the tool. (b) $\mu$ EDM milling of the part.

\subsection{Microtool fabrication}

The experimental set up for the tool fabrication is described in more detail in Fig. 2. A tungsten rod is immersed in a vat containing the electrolyte $(5 \mathrm{Mol} / \mathrm{L}$ $\mathrm{NaOH}$ with $50 \%$ glycerol). The vat contains a cylindrical platinum grid used for the counter-electrode, a supporting dielectric liquid (non-mixable with the electrolyte), and a small container filled with Gallium-
Indium. To start the process, a $250 \mu \mathrm{m}$ diameter rod and $20 \mathrm{~mm}$ height, is vertically translated until electrical contact is made with the Ga-In (Fig 2a). The electrochemical dissolution process is then started. The lower part of the rod (in the dielectric) is unchanged during the process whilst the intermediate part (in the electrolyte) is made thinner (Fig 2b). The resulting shape resembles a dumb-bell. When the target tool diameter is obtained, the rod is translated upward in order to place the lower part of the dumb-bell at the air-electrolyte interface (Fig 2c). A cut off voltage is then applied for a short duration in order to remove the lower part of the dumb-bell and free the microtool, which is now ready for the $\mu$ EDM process (Fig $2 d$ ).

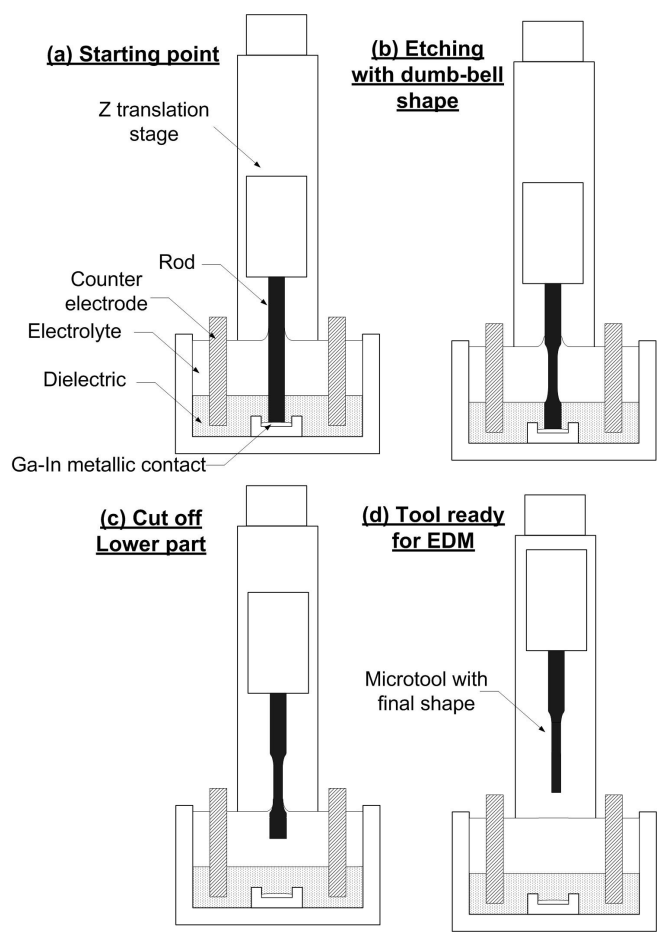

Figure 2. Principle of microtool fabrication. (a) Initial setup of the fabrication process. (b) Etching occurs only on the section of the rod exposed to the electrolyte. (c) Bottom section of the dumb-bell is removed. (d) Tool fabrication is complete.

The objective of the tool fabrication process is to greatly reduce the diameter of the rod while conserving its cylindrical geometry. As mentioned above, electrochemical etching of a rod leads to a conical shape unless a specific voltage waveform is applied. The applied voltage waveform is shown in Fig. 3 . Thin cylindrical tools can be obtained by applying alternating voltage pulses with a $50 \mathrm{~Hz}$ frequency between the rod and the counter-electrode with appropriate time of application TON, rest time TOFF, and current amplitude. The length of the tool is directly related to the height of the electrolyte. An example of a fabricated tungsten microtool with $10 \mu \mathrm{m}$ diameter over an $800 \mu \mathrm{m}$ length is provided in Fig. 4. Typical process parameter values are shown in Table 1 for the above mentioned tungsten rod. Fig. 5 shows a view of a second tungsten microtool with a $4 \mu \mathrm{m}$ diameter over a $300 \mu \mathrm{m}$ length. 


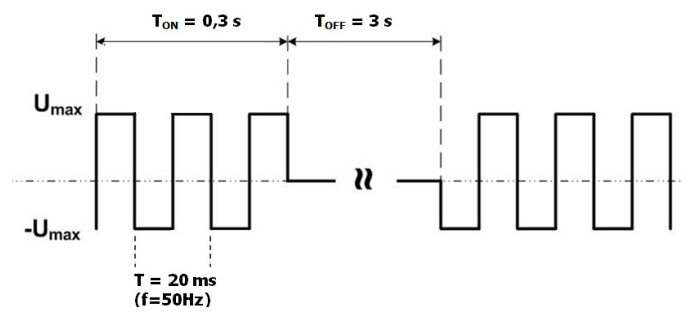

Figure 3. Voltage pulses applied between the tool and counter-electrode voltage.

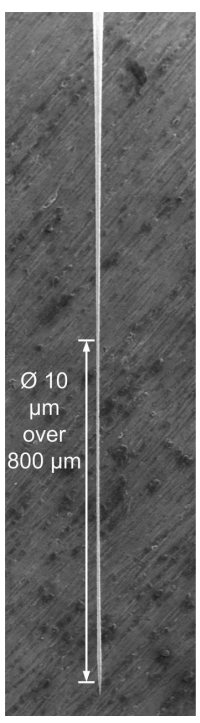

Figure 4. SEM view of a fabricated tungsten microtool with $10 \mu \mathrm{m}$ diameter over an $800 \mu \mathrm{m}$ length.

Table 1. Typical process parameter values for the electrochemical preparation of the tungsten tool shown in Fig. 4 (31 minutes fabrication time).

\begin{tabular}{|c|c|c|c|}
\hline & Time (s) & Current (mA) & $\mathrm{T}_{\mathrm{ON}} / \mathrm{T}_{\mathrm{OFF}}(\mathrm{s})$ \\
\hline Step 1 & 1000 & 200 & $0.2 / 1$ \\
\hline Step 2 & 400 & 100 & $0.2 / 1$ \\
\hline Step 3 & 100 & 100 & $0.1 / 1$ \\
\hline Step 4 & 50 & 100 & $0.05 / 1$ \\
\hline
\end{tabular}

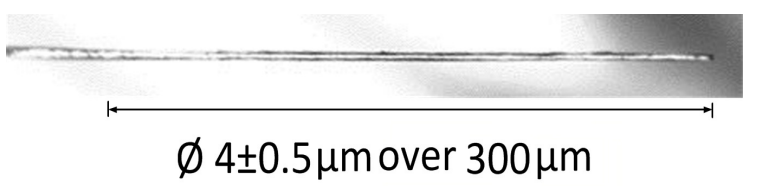

Figure 5. Image of a second tungsten tool (diameter estimated by optical microscope).

\section{3. $\mu E D M$ milling machine}

Fig. 6 is a simplified view of the electronics of the $\mu E D M$ milling machine. The electrical micro discharges are generated with a $R_{M} C_{M}$ generator with $\theta_{\text {ON }} / \theta_{\text {OFF }}$ duty cycle monitored with a $16 \mathrm{MHz}$ 8-bit Atmel microcontroller. The principle is (1) to keep the high side MOSFET closed and the low side MOSFET opened during the $\theta_{\mathrm{ON}}$ time and (2) to keep the high side MOSFET opened and the low side MOSFET closed during the $\theta_{\text {off }}$ time. For this appropriate level shift is necessary due to the floating voltage of point $A$ in Fig. 6.

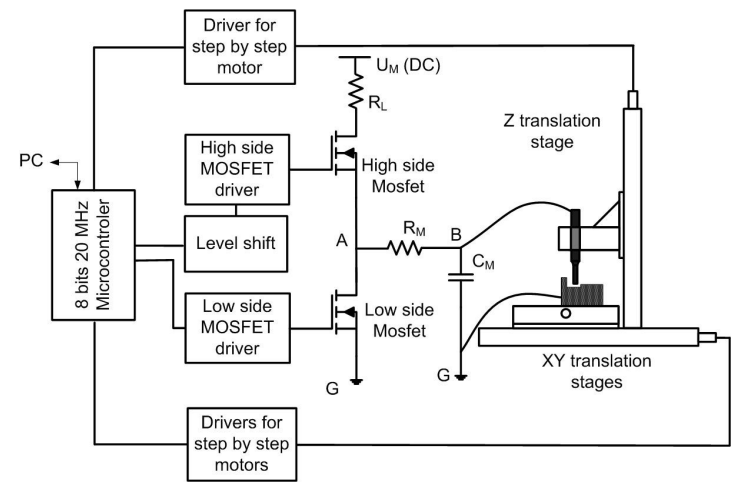

Figure 6 . Electronics of the $\mu$ EDM milling machine.

During $\theta_{\mathrm{ON}}$ time, if the tool is close enough to the part, the fast discharge of the capacitance $\mathrm{C}_{M}$ leads to the machining of the part through creation of a microplasma. With our setup, the duration of the plasma is about 400 ns as shown in Fig. 7. Only a few micro discharges are possible during each $\theta_{\mathrm{ON}}$ depending on the ratio between $R_{M} C_{M}$ and $\theta_{O N}$, which limits the amount of energy passing trough the tiny microtool.

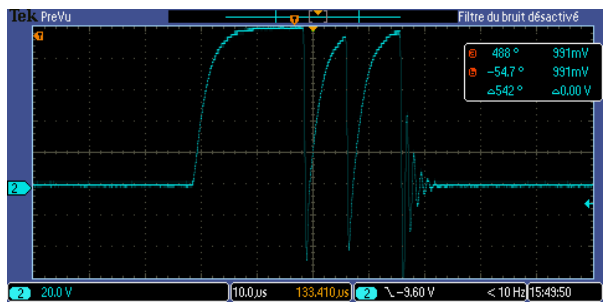

Figure 7. Voltage $V_{B G}$ across capacitance showing 2 discharges during $\theta_{\mathrm{ON}}\left(100 \mathrm{~V} \mathrm{U}_{\mathrm{M}}, 10 \mathrm{nF} \mathrm{C}_{\mathrm{M}}, 50 \mu \mathrm{s} \theta_{\mathrm{ON}}\right.$, $100 \mu \mathrm{s} \theta_{\text {OFF }}$.

\subsection{Examples of machining}

Fig. 8 and 9 show examples of microfluidics channels machined respectively in polished 20-by-20by $0.6 \mathrm{~mm}$ stainless steel $316 \mathrm{Ti}$ and unpolished titanium using tungsten microtools similar to the one in Fig. 4. The channel width and depth are respectively approximately $40 \mu \mathrm{m}$ and $15 \mu \mathrm{m}$, for stainless steel 316 $\mathrm{Ti}$ and $25 \mu \mathrm{m}$ and $8 \mu \mathrm{m}$ for titanium. Preliminary experiments have shown that the tool wear ratio is in the $0.1-10 \%$ range depending on the machining parameters (voltage, average gap value, flow of deionised water, etc.). 


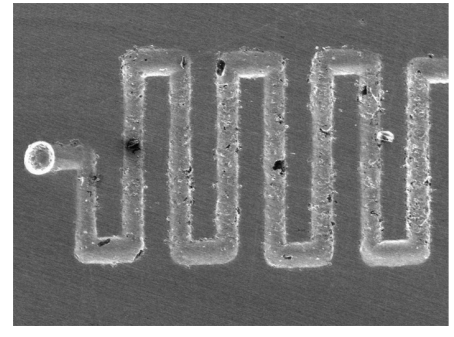

Figure 8. SEM view of approximately $40 \mu \mathrm{m}$ wide and $15 \mu \mathrm{m}$ deep channels in stainless steel $316 \mathrm{Ti}$. Machining parameters: $100 \mathrm{~V} \mathrm{U}, 100 \Omega \mathrm{R}_{\mathrm{M}}, 10 \mathrm{nF} \mathrm{C}_{\mathrm{M}}$, $5 \mu \mathrm{m} / \mathrm{s}$ speed for $X Y Z$ axis.

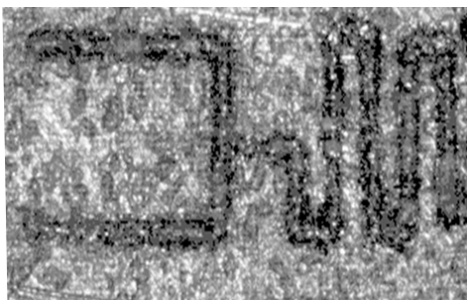

Figure 9. Optical microscope view of $25 \mu \mathrm{m}$ wide and $8 \mu \mathrm{m}$ deep channels in bulk titanium. Machining parameters: $100 \mathrm{~V} \mathrm{U} \mathrm{U}_{\mathrm{M}}, 100 \Omega \mathrm{R}_{\mathrm{M}}, 10 \mathrm{nF} \mathrm{C}_{\mathrm{M}}, 5 \mu \mathrm{m} / \mathrm{s}$ speed for $\mathrm{XYZ}$ axis.

\subsection{Resolution of the $\mu E D M$ machining in dry EDM}

Fig. 10 illustrates the potential of this process with an example of EDM machining with a single micro discharge performed on $\mathrm{p}+$ silicon in dry air (not deionized water) with a platinum-iridium tool. Machining resolution in the micrometric range is thus demonstrated with this simple experiment. Therefore, an improved version of the $\mu$ EDM milling machine is in development in our laboratory to allow taking full advantage of this resolution.

\section{Conclusion}

A new method for the fabrication of thin cylindrical microtools has been reported with successful application to $\mu \mathrm{EDM}$ milling. The fabrication of the tool by electrochemical dissolution is straightforward and performed with simple equipment allowing the tool fabrication and the $\mu$ EDM milling to be incorporated in the same machine. Preliminary results on the machining of stainless steel and titanium parts have been provided.

Future work will concern the characterization of the tool fabrication process. The repeatability of the etching will be evaluated with a $10 \mathrm{~nm}$ resolution LSM-500S Mitutoyo laser micrometer. Preliminary results show consistent data with the values of Fig. 4 and 5 . The fabrication time of the tool can be significantly reduced, probably down to 10 minutes, but this requires careful optimization. To increase productivity, parallel fabrication of microtools will be considered. Future work will also concern the improvement of the $\mu$ EDM milling machine to take full advantage of the potential of the process.
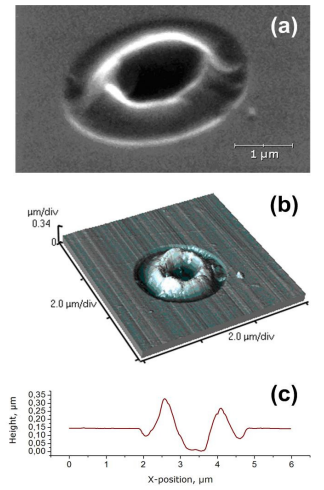

Figure 10. Crater formed after a single spark on $\mathrm{p}+$ $(0.005 \Omega \cdot \mathrm{cm})$ silicon $\left(4.7 \mathrm{nF} \quad \mathrm{C}_{\mathrm{M}}, \quad 30 \mathrm{~V} \quad \mathrm{U}_{\mathrm{M}}\right)$ (a) SEM image, (b) AFM image, (c) AFM profile.

\section{Acknowledgements}

This work was financed by grant L356 of Lyon Science Transfert (with support from the PRES of Lyon, the ANR, the FEDER, the Région Rhône Alpes and the Grand Lyon) and the FUI ConProMi. G. Girardin acknowledges the support of the CNRS and DGA for a PhD grant.

\section{References}

[1] Pham DT, Dimov SS, Bigot S, Ivanov A and Popov K. Micro-EDM-recent developments and research issues. J. Mat. Proc. Tech. 149 (2004) 50-57.

[2] Lim HS, Wong YS, Rahman M and Edwin Lee MK. A study on the machining of high-aspect ratio micro-structures using micro-EDM. J. Mat. Proc. Tech. 140 (2003) 318-325.

[3] Masuzawa T, Fujino M and Kobayashi K. Wire electro-discharge grinding for micro-machining. CIRP Annals 34 (1985) 431-434.

[4] Kawakami T and Kunieda M. Study on Factors Determining Limits of Minimum Machinable Size in Micro EDM. CIRP Annals 54 (2005) 167-170.

[5] Lim HJ, Lim YM and Kim SH. Fabrication of arbitrarily shaped microelectrodes by electrochemical etching. Jpn. J. Appl. Phys. 42 (2003) 1479-1485.

[6] Benilov A, Skryshevsky V, Robach $Y$ and Cabrera M. Micro and nano electrical discharge machining in microfluidics and micro nanotechnology. Int. J. Mater. Form. Suppl 1 (2008) 1315-1318.

[7] Melmed AJ. The art and science and other aspects of making sharp tips. J. Vac. Sci. Technol. B 9 (1991) 601-608.

[8] Cabrera M. Machine et procédé d'usinage d'une pièce par micro-électroérosion. Patent application PCT/EP2009/061683.

[9] Cabrera M, Girardin G, Morin P, Layouni $Y$ and Semet V. Procédé et dispositif de fabrication d'un cylindre de diamètre micrométrique, demande de brevet français FR10/01407 (06/04/2010). 